\title{
Corrosion Behavior of Printed Circuit Boards in Tropical Marine Atmosphere
}

\author{
Yali Feng ${ }^{1,2}$, Ziheng Bai ${ }^{1,2}$, Qiong Yao $^{3}$, Dongjiu Zhang ${ }^{3}$, Jialiang Song ${ }^{1,2}$,Chaofang Dong ${ }^{1,2}$, \\ Junsheng $W^{1,2}$, Kui Xiao ${ }^{1,2, *}$ \\ ${ }^{1}$ Corrosion and Protection Center, Institute of Advanced Materials and Technology, University of \\ Science and Technology Beijing, Beijing 100083, China. \\ 2.National Materials Corrosion and Protection Data Center, University of Science and Technology \\ Beijing, Beijing 100083, China. \\ ${ }^{3}$ Key Laboratory of Space Launching Site Reliability Technology, Haikou 571000, China. \\ *E-mail: xiaokui@ustb.edu.cn
}

doi: $10.20964 / 2019.12 .73$

Received: 25 June 2019 / Accepted: 7 September 2019 / Published: 29 October 2019

\begin{abstract}
Outdoor exposure experiments of PCB-Cu, PCB-ImAg and PCB-ENIG were conducted in a tropical marine atmosphere under the synergistic effect of multiple factors, and the corresponding corrosion behavior of the PCBs was investigated by SEM, EDS and EIS. The results indicated that PCB-ImAg had strong resistance to $\mathrm{Cl}^{-}$, and the surface was covered only by several spores, without obvious corrosion products, and it had excellent corrosion resistance. PCB-ENIG was covered with dense corrosion products, and it had poor biocompatibility and was detrimental to the growth of molds. PCB$\mathrm{Cu}$ was significantly corroded, and an obvious shedding of surface corrosion products was observed, with the corrosion rate increasing constantly during the exposure periods. All the corrosion occurred at the active sites where dust particles, salt particles and mold spores were scattered. The probable corrosion mechanism of PCBs inferred that defects in the coatings of PCB-ImAg and PCB-ENIG acted as pathways for the corrosive electrolyte liquid, and the copper substrate was corroded, and localized corrosion cells accelerated the corrosion. Additionally, long-term exposure led to the formation of a double-layer structure in PCB-Cu, with an inner oxide film and an outer layer of loose corrosion products, consequently providing a weak protection effect.
\end{abstract}

Keywords: Corrosion; PCB; Tropical marine atmospheric environment; Exposure experiments.

\section{$\underline{\text { FULL TEXT }}$}

(C) 2019 The Authors. Published by ESG (www.electrochemsci.org). This article is an open access article distributed under the terms and conditions of the Creative Commons Attribution license (http://creativecommons.org/licenses/by/4.0/). 
